\title{
EXPERIMENTO COM ABACATE, BORRA DE CAFÉ, LICURI E LEITE DE COCO PARA EXTRAÇÃO DE ÓLEO, PRODUÇÃO DE BIODIESEL E ANÁLISE ESPECTRAL
}

Silvio Cunha ${ }^{\mathrm{a}, \mathrm{b}, *}$, Marina Costa Rodrigues ${ }^{\mathrm{a}, \mathrm{b}}$, Rosiene Reis Mattos ${ }^{\mathrm{a}, \mathrm{c}}$, Leonardo Sena Gomes Teixeira ${ }^{\mathrm{a}, \mathrm{b}}$, Airam Oliveira Santos ${ }^{c}$, Elaine V. Santos , Rauan S. Souzac, Givaldo dos Santos Andraded, Rodrigo De Paula ${ }^{d}$ e Djane S. de Jesus ${ }^{e}$

anstituto de Química, Universidade Federal da Bahia, Campus de Ondina, 40170-115 Salvador - BA, Brasil

'Instituto Nacional de Ciência e Tecnologia em Energia e Ambiente, Universidade Federal da Bahia, Campus de Ondina, 40170290 Salvador - BA, Brasil

'Instituto Federal de Educação, Ciência e Tecnologia Baiano, Campus Senhor do Bonfim, Caixa Postal 55, 48970-000, Senhor do Bonfim - BA, Brasil

${ }^{\mathrm{d} C e n t r o ~ d e ~ F o r m a c ̧ a ̃ o ~ d e ~ P r o f e s s o r e s, ~ U n i v e r s i d a d e ~ F e d e r a l ~ d o ~ R e c o ̂ n c a v o ~ d a ~ B a h i a, ~ 45300-000, ~ A m a r g o s a ~-~ B A, ~ B r a s i l ~}$

'Instituto Federal de Educação, Ciência e Tecnologia da Bahia, Campus Salvador, Rua Emídio dos Santos, s/n - Barbalho, 40301015 Salvador - BA, Brasil

Recebido em 30/09/2017; aceito em 19/02/2018; publicado na web em 08/03/2018

\begin{abstract}
AVOCADO, SPENT COFFEE GROUNDS, LICURI AND COCONUT MILK FOR OIL EXTRACTION, BIODIESEL PRODUCTION, AND SPECTRAL ANALYSIS. An undergraduate organic chemistry experiment for oil extraction and biodiesel production using alternative biomass was developed, whereby oils of avocado, coconut and spent coffee grounds were obtained and submitted to transesterification reaction with $\mathrm{CH}_{3} \mathrm{OH}$ under $\mathrm{NaOH}$ catalysis. Avocado and coffee oils were obtained by typical extraction and coconut oil was obtained through water evaporation of coconut milk in a domestic microwave oven. The commercial oil of licuri (Syagrus coronate), a Brazilian native biomass, was also converted to biodiesel. All four oils and four biodiesels were characterized by ${ }^{1} \mathrm{H}-\mathrm{NMR}$ and FTIR, and a comparative study of these spectra reveled that FTIR analyses alone provides enough information to discriminate between oil and biodiesel and confirm transesterification reaction. Besides, the unsaturation degree of all oils was determined by ${ }^{1} \mathrm{H}-\mathrm{NMR}$. A mechanistic proposal concerning the role of $\mathrm{NaOH}$ catalysis is presented, excluding the sodium methoxide formation.
\end{abstract}

Keywords: biodiesel; transesterification; undergraduate organic chemistry experiment.

\section{INTRODUÇÃO}

A formação contemporânea dos profissionais da Química com ênfase na sustentabilidade demanda o treinamento experimental em Química Verde, sendo assim desejável o emprego de biomassa como fonte renovável de reagente químico. Se, além do reagente, o produto da reação é intrinsicamente associado ao tema ambiental e tecnológico, a aula tende a capturar a atenção do estudante e intensificar seu envolvimento com o experimento. A produção de biodiesel contempla todos estes aspectos e, não por acaso, existem várias propostas de aulas onde o tema biodiesel é abordado, Figura $1 .^{1-11}$

Desde a contribuição seminal de Donaghy e colaboradores em $2006,{ }^{2}$ que descreveram a primeira proposta de ensino para a produção de biodiesel empregando óleo de soja comercial e o residual de fritura, $\mathrm{NaOH}$ como catalisador e metanol como agente de transesterificação, caracterizando tanto os óleos quanto produto por espectroscopias de absorção molecular no infravermelho (IV) e de ressonância magnética nuclear de hidrogênio (RMN de Hidrogênio), estes dois óleos da mesma biomassa prevalecem como matéria-prima na maioria dos experimentos didáticos. Contudo, há relatos propondo alternativas como borra de café, ${ }^{11}$ sementes de jojoba ${ }^{10}$ óleos de arroz, uva e pequi. ${ }^{3}$ Há também predominância da catálise básica, e algumas preparações didáticas de biodiesel empregam procedimentos mais complexos, utilizando catálise básica e em sequência catálise ácida para a esterificação dos ácidos graxos livres, avaliando o teor de catalisador e a consequente saponificação. ${ }^{3}$

\footnotetext{
*e-mail: silviodc@ufba.br
}

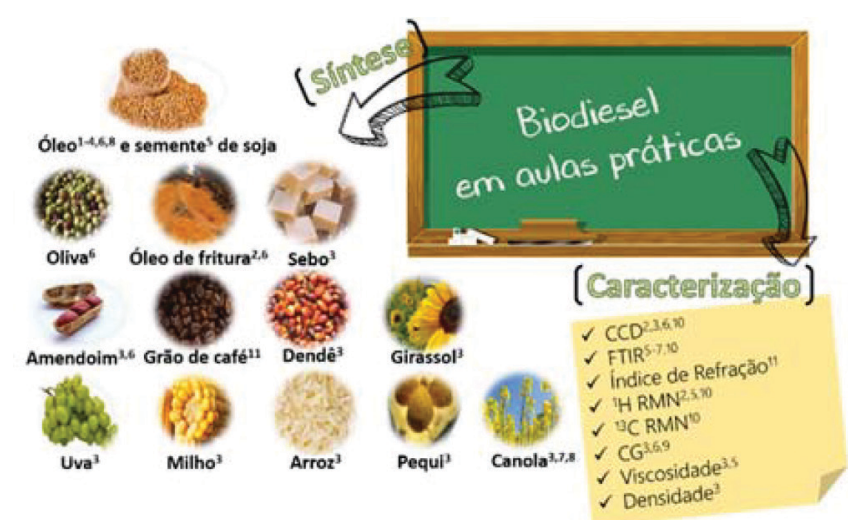

Figura 1. Biomassas empregadas na síntese de biodiesel em aulas experimentais e caracterizações típicas

Apesar destas significativas contribuições à disseminação da produção e caracterização de biodiesel em experimentos destinados ao treinamento laboratorial, há ainda demanda por experimentos de química orgânica nos quais o estudante produza o óleo e o transforme no biodiesel, e que empregue biomassas alternativas para estes fins. ${ }^{12}$ Adicionalmente, a análise espectral do óleo e do biodiesel é feita entre estes, não sendo encontrada a análise espectral comparativa entre os óleos e entre os biodieseis.

Face ao nosso envolvimento com a transposição didática de temas atuais no ensino experimental de química orgânica verde, ${ }^{13}$ descrevemos aqui o emprego de biomassas alternativas na produção do biodiesel em aulas de graduação: abacate (Persea americana), leite 
de coco (Cocos nucifera), borra de café e licuri (Syagrus coronata), com ênfase na extração do óleo dos três primeiros e que, para além da produção do biodiesel de todas as biomassas, realiza a análise espectral comparativa dos triglicerídeos e biodieseis.

\section{RESULTADOS E DISCUSSÃO}

\section{Extração dos óleos das biomassas alternativas para aula de química orgânica}

Na maioria dos experimentos didáticos de produção de biodiesel a matéria-prima é o óleo de soja comercial ou o residual de fritura. Todavia, Fontoura e colaboradores descreveram a preparação de biodiesel em aula de química orgânica empregando doze diferentes matérias-primas, incluindo soja e sebo, sendo o mais amplo trabalho de comparação de óleos já realizado em aulas experimentais de biodiesel. ${ }^{3}$ Em todos estes experimentos o óleo empregado foi sempre o comercial, e só recentemente a extração do óleo foi proposta como parte integrante da aula de obtenção do biodiesel de jojoba (Simmondsia chinensis) ${ }^{10}$ e da borra de café, ${ }^{11}$ ou a extração dos triglicerídeos de várias sementes, incluindo café, soja e girassol. ${ }^{5}$

Apesar do valor pedagógico destas propostas, é desejável que o profissional da química esteja habilitado no isolamento de óleos de fontes renováveis empregando diversas técnicas de obtenção dos triglicerídeos em laboratório de química orgânica. Para contribuir no saneamento desta lacuna, a presente proposta engloba a obtenção do óleo de abacate, de coco e da borra residual de café, Figura 2.

A seleção das biomassas alternativas levou em consideração a facilidade de acesso às mesmas. $\mathrm{O}$ abacate é um fruto sazonal amplamente difundido no Brasil, e o óleo de coco é comercialmente disponível, mas é o mais caro dentre os aqui estudados. Porém, é facilmente obtido do leite de coco disponível comercialmente. A borra de café é um resíduo facilmente encontrado, e sua inserção na aula tem o aspecto de aproveitar uma biomassa que é descartada no lixo. ${ }^{14} \mathrm{O}$ licuri é uma planta muito difundida no nordeste brasileiro, e encerra este aspecto regional. Portanto, na obtenção do biodiesel foi empregado seu óleo comercial, em função do acesso restrito ao fruto fora da região Nordeste. Adicionalmente, para a produção dos óleos foram empregados três procedimentos distintos, de forma que o conjunto dos estudantes passa a conhecer uma diversidade de técnicas experimentais de obtenção de óleo.

Como estratégia das aulas, propõe-se a realização dos experimentos em duplas de estudantes por biomassa, ao longo de duas aulas de 3-4 h de duração, e que cada dupla fique responsável por um tipo de biomassa uma vez que o tempo limitado da aula não permite que a mesma equipe realize todas as operações para todas biomassas. Na primeira aula realiza-se a extração do óleo e, na segunda, a transesterificação e obtenção dos espectros. O professor deve adequar a estratégia da aula em função da natureza do curso e da infraestrutura do laboratório de ensino. No final das duas aulas as informações das equipes são compartilhadas para a realização da análise espectral comparativa, como adiante descrito.

\section{Extração do óleo de abacate}

Empregar o fruto do abacateiro como matéria-prima para a produção de biodiesel causa nos estudantes uma sensação próxima do espanto da descoberta, que a princípio não associam um fruto que consomem com alguma regularidade à possibilidade de produção de óleo e subsequente transformação.

Apesar de haver proposta de aula experimental de bioquímica aplicando abacate para caracterização dos seus triglicerídeos através da transesterificação, ${ }^{15}$ não há proposta específica de aula visando a obtenção do óleo de abacate para produção de biodiesel.

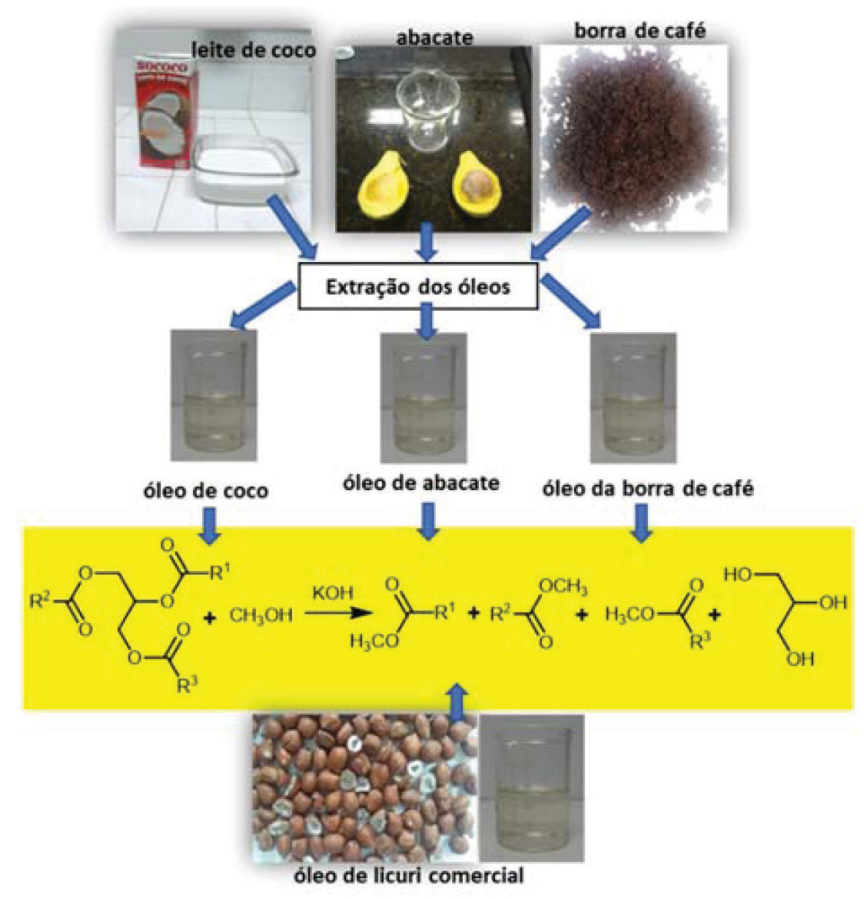

Figura 2. Obtenção dos óleos e produção dos biodieseis

Para extração do óleo, $200 \mathrm{~g}$ da polpa do abacate foram convertidas em uma pasta homogênea e submetida a secagem em estufa. O material semissólido desidratado foi submetido a extração contínua em aparelho Soxhlet, fornecendo $14 \mathrm{~mL}$ de óleo verde após eliminação do hexano, correspondendo ao consumo de $21 \mathrm{~mL}$ de hexano $/ \mathrm{mL}$ de óleo obtido. $\mathrm{O}$ óleo foi caracterizado por IV e RMN e submetido à reação de transesterificação para a produção de biodiesel, adiante descrita.

\section{Extração do óleo da borra de café}

Enquanto abacate, licuri e leite de coco têm finalidade alimentar reconhecida e com pouca geração de resíduo, o consumo destes alimentos não é comparável ao que consumimos diariamente de café. O cafezinho faz parte do nosso cotidiano e seu consumo gera resíduo sólido tanto na indústria de café solúvel quanto devido ao hábito de beber café coado em casa, no trabalho e nas redes de lanchonetes e restaurantes. Em Salvador da Bahia, existem trabalhadores do asfalto que têm como fonte de renda a venda de café em carrinho típico que já faz parte do folclore moderno, tanto assim que o carrinho de café da Bahia é motivo de concursos e matéria jornalística em programas locais de televisão. ${ }^{16,17}$

A borra da indústria do café solúvel é um resíduo cujo aproveitamento tem sido motivo de pesquisa, pois estima-se que $34 \mathrm{t}$ de borra de café são produzidas por dia, o que representa um potencial para a produção de 1,5 t de óleo, mas a borra do café doméstico é descartada no lixo sem qualquer aproveitamento. ${ }^{14}$ Por esse aspecto, decidimos incorporar esta biomassa residual no experimento didático, pois assim intensifica os princípios da Química Verde. A borra do café pode ser coletada tanto nas residências dos estudantes quanto no próprio local onde a extração do óleo será realizada.

No relato disponível na literatura para a extração do óleo de café e produção do biodiesel em aula de graduação, o solvente empregado na extração foi o heptano, e o procedimento para a produção do biodiesel empregou catálise ácida numa reação de transesterificação que durou $24 \mathrm{~h} .{ }^{11}$ No procedimento aqui desenvolvido empregamos extração a quente com hexano como solvente extrator por ser mais acessível aos laboratórios de ensino, e catálise básica na produção do biodiesel para que a aula possa ser executada num único dia. 
O rendimento do óleo é muito variável, pois o teor de óleo contido na borra é dependente do tipo e da qualidade do pó de café usado, bem como do modo de preparo da bebida. $\mathrm{O}$ rendimento ficou entre 4-5\% nas diversas vezes que a extração foi realizada, representando o consumo de $98 \mathrm{~mL}$ de hexano/mL de óleo obtido, que foi caracterizado por IV e RMN e convertido a biodiesel.

\section{Produção do óleo de coco}

Existem descrições de produção de biodiesel empregando óleo de $\operatorname{coco},{ }^{18}$ mas nenhuma que execute a produção do óleo em aula de química orgânica. Para a obtenção do óleo do coco no contexto da aula experimental, desenvolvemos um procedimento diferente do tradicionalmente ensinado nos cursos práticos, onde a extração por partição sólido-líquido com solvente apolar é o princípio empregado. Na produção do óleo de coco o material de partida foi o leite de coco comercial, e o procedimento consiste da evaporação da água da emulsão que é o leite de coco, o que foi realizado em um forno de micro-ondas doméstico. Por este motivo, a produção do óleo de coco demanda o menor volume de solvente extrator dentre os óleos aqui produzidos. Duas marcas de leite de coco foram testadas, mas apenas com a marca Sococo o experimento foi reprodutível.

Uma amostra de $300 \mathrm{~g}$ do leite de coco foi desidratada em um tempo total de $23 \mathrm{~min}$. Os cuidados neste experimento estão relacionados ao controle do superaquecimento durante a desidratação, que leva à carbonização da amostra e projeção do material na cavidade do forno. Para evitar estes fatos, a desidratação deve ser conduzida em recipiente de vidro refratário, como as assadeiras de vidro comumente utilizadas nas residências para processar alimentos ao forno, as quais maximizam a superfície de evaporação do líquido; quanto maior essa superfície, mais eficaz a evaporação. O recipiente deve ser coberto com filme plástico, destes que são empregados para recobrir alimentos, e vários orifícios são perfurados para a saída do vapor d'água (ver Figura 4S). Para a massa acima indicada, o aquecimento é interrompido a cada 5 min e o formo é deixado esfriar com a porta aberta por $1 \mathrm{~min}$, quando novo ciclo de aquecimento se inicia, sendo este procedimento seguido até o tempo total indicado. Aquecimento ininterrupto causa a carbonização extensiva do material e perdas por projeção devido à evaporação intensa da água.

Forma-se um resíduo oleoso e um material sólido parcialmente carbonizado, sendo o óleo escoado e o recipiente lavado com hexano para remover o óleo residual. O óleo amarelo resultante torna-se incolor ao ser tratado com carvão ativado, e rendeu $64 \mathrm{~mL}$, o que representa o consumo de $1 \mathrm{~mL}$ de hexano/mL de óleo obtido (ver detalhes no experimental e Figura 4S).

A obtenção do óleo de coco é realizada em no máximo uma hora, desde a pesagem da amostra à quantificação do óleo, que foi caracterizado por IV e RMN e convertido a biodiesel. O espectro na região do IV do óleo aqui produzido (Figura 4S) foi idêntico ao de uma amostra de óleo comercial (Figura 18S).

Além do emprego do forno de micro-ondas doméstico, esta é a primeira proposta de aula experimental de química para a produção do óleo de coco e subsequente produção do biodiesel. Como efeito colateral, o laboratório é tomado pelo agradável aroma de cocada, que alegra a todos.

\section{Produção de biodiesel das biomassas alternativas para aula de química orgânica}

De posse do óleo de cada biomassa alternativa, alíquotas foram empregadas em reação de transesterificação para a produção do respectivo biodiesel empregando metanol e catálise básica, Figura 2. Considerando a reação geral da transesterificação, um mol de triglicerídeo reage com três mols de álcool, formando três mols de ésteres alquílicos e um mol de glicerol como coproduto. Excesso de álcool favorece o deslocamento do equilíbrio para o sentido da formação dos ésteres e influencia diretamente nas propriedades físico-químicas do biodiesel formado. Dessa forma, a proporção 6:1 é geralmente adotada como proporção molar de álcool em relação ao triglicerídeo, acarretando em produto de acordo com as especificações internacionais e minimizando a presença de intermediários como mono ou diglicerídeos. ${ }^{19}$

Nos procedimentos descritos na literatura de ensino de química, a produção de biodiesel é realizada empregando uma proporção volumétrica entre o óleo e o álcool (geralmente metanol), o que resulta em proporção molar entre o triglicerídeo e o álcool diferente da proporção acima mencionada em trabalhos de pesquisa. ${ }^{1-11}$ São indicadas proporções em volume entre o óleo, geralmente de soja, e o metanol que variam de 25 a 40\%. Apesar de não ser claramente explicitado, parece que esta redução do volume de metanol objetiva minimizar a exposição dos estudantes a este álcool, reconhecidamente tóxico.

A substituição do metanol por etanol poderia ser uma alternativa mais aderente aos princípios da química verde, mas sabe-se que a síntese do biodiesel etílico é operacionalmente mais complexa que o metílico e que as transesterificações etílicas são mais lentas e necessitam maiores quantidades de álcool e catalisador, o que diminui o êxito quando aplicada em aulas. ${ }^{19}$ Por estas razões, o procedimento foi executado com metanol na proporção volumétrica indicada nos textos destinados a aula experimental, embora o uso de etanol pudesse contemplar apropriadamente a proposta verde do projeto.

Nas biomassas deste trabalho, os óleos de abacate, borra de café e licuri sofreram transesterificação com metanol na razão molar MeOH:óleo de 8,5, 8,2 e 6,3:1, respectivamente, mantendo constante a razão molar KOH:óleo $(0,1)$. Para o óleo de coco não foi observada separação de fases entre o glicerol e o biodiesel com estas proporções, indicando que a transesterificação não foi completa. Assim, adotou-se proporção molar de 6,2:1 de metanol em relação ao óleo, a qual permitiu melhor transferência de massa durante a reação, emulsão menos estável e consequente melhor rendimento. $\mathrm{Na}$ obtenção do biodiesel da borra de café a relação de 2,5:1 do óleo com o metanol foi suficiente para a produção do biodiesel.

Os rendimentos obtidos para os biodieseis das quatro biomassas estudadas estão indicados na Tabela 1, e foram calculados através da razão dos volumes de biodiesel formado e de óleo utilizado, em analogia aos diversos textos de preparação de biodiesel para aulas experimentais. ${ }^{1-11}$ É importante destacar que este é o primeiro relato sobre o uso dos óleos de abacate e licuri como matérias-primas para a produção de biodiesel em aula experimental.

\section{Análise espectral comparativa dos óleos e biodieseis}

Fontoura e colaboradores, na sua excelente proposta de aula de óleos e gorduras em química orgânica, conduzem os estudantes à realização da análise comparativa de diversas varáveis físico-químicas dos óleos e gorduras e dos biodieseis, inclusive com a análise da mistura dos ésteres metílicos dos biodieseis por cromatografia em fase gasosa. ${ }^{3}$ Destarte, apesar do significativo valor pedagógico deste trabalho, não houve a execução da análise comparativa das matérias-primas e produtos via IV e RMN.

Nos experimentos didáticos que empregam o tema biodiesel e caracterizam o produto e a matéria-prima por IV e/ou RMN, a comparação dos espectros do óleo original com o biodiesel é feita para a certificação da ocorrência da reação química, não explorando o potencial didático da comparação entre os vários óleos e entre seus correspondentes biodieseis. A maioria dessas propostas didáticas emprega RMN para esta caracterização, algumas associam RMN e IV, e poucas usam exclusivamente o IV. ${ }^{5,6,8,18,20}$ 
Na proposta dos nossos trabalhos de transposição didática para desenvolver experimentos sustentáveis de química orgânica, é crucial que a execução seja possível em diferentes contextos de infraestrutura de ensino experimental, com materiais de fácil acesso e que contemplem a existência de mínimo parque instrumental, mas ainda proporcione o máximo valor pedagógico. Assim, empregamos aqui correlações entre IV e RMN, de forma que nos locais onde o acesso a RMN para aulas de graduação seja limitado se possa, empregando $\mathrm{IV}$, chegar às mesmas conclusões.

Na Figura 3 são apresentados os espectros parciais de RMN de ${ }^{1} \mathrm{H}$ dos óleos e seus correspondentes biodieseis (espectros completos no Material Suplementar) obtidos em espectrômetro dedicado ao ensino, onde é possível verificar o desaparecimento dos sinais dos hidrogênios metilênicos carbinólicos da porção glicerina dos triglicerídeos $\left(\mathrm{OCH}_{2}: \delta 4,00-4,50 \mathrm{ppm}\right)$ e o aparecimento do singleto da metoxila no biodiesel $\left(\mathrm{OCH}_{3}: \delta 3,54 \mathrm{ppm}\right)$, o que comprova a ocorrência da reação de transesterificação com metanol.

Para comprovar a ocorrência da reação de transesterificação, diversos parâmetros podem ser invocados, como a cromatografia em camada delgada (CCD), teste de combustão, ${ }^{3}$ sendo o espectro de RMN um deles. As propostas de experimento de graduação que empregam como técnica de análise espectral exclusivamente RMN ignoram o IV ou tendem a minimizar a análise por IV para diferenciar o triglicerídeo do biodiesel, chegando até mesmo a afirmar que os "IVs de lipídios e biodieseis são praticamente idênticos e difíceis de distinção visual". ${ }^{20}$ Esta é uma afirmação muito imprecisa pois usam como exemplo para sustentar o não emprego do IV a absorção de éster, desconsiderando a riqueza de detalhes da espectrometria na região do IV. Num texto didático de química orgânica que se pretende formativo, desconsiderar uma técnica de elucidação estrutural em detrimento de outra ou minimizar sua potencialidade não é apropriado para a formação plena do futuro químico, e não corresponde à atuação profissional nas fábricas, institutos de pesquisa e instituições de ensino de profissionais da Química.

É possível empregar também a análise do IV para comprovar a ocorrência da reação para além da função éster. Dessa forma, na
Figura 4 estão agrupadas porções dos espectros na região do infravermelho (1500-1000 $\mathrm{cm}^{-1}$ ) dos óleos e dos biodieseis das quatro biomassas alternativas estudadas onde, através de uma simples inspeção visual, é possível distinguir triglicerídeos de seus biodieseis. Em particular, são úteis as comparações das bandas de absorções presentes nos triglicerídeos em 1464-1470 e 1456 cm$^{-1}$ (como um ombro da primeira); nos biodieseis existem as mesmas absorções em 1462-1464 e $1456 \mathrm{~cm}^{-1}$ (também como um ombro da primeira) mas sempre seguida da absorção em $1435 \mathrm{~cm}^{-1}$ (inexistente no triglicerídeo). Adicionalmente, nos triglicerídeos sempre ocorre a banda larga em 1153-1163 cm-1, enquanto que no biodiesel esta absorção desaparece e dá lugar ao conjunto de absorção em 1196 e 1169-1171 $\mathrm{cm}^{-1}$. Este conjunto de bandas aditivas à banda da função éster metílico permite o diagnóstico preciso da ocorrência da reação e distinção entre matéria-prima e produto.

As mudanças no IV acima mencionadas são bem descritas na literatura de caracterização de biodiesel ${ }^{21}$ porém, até onde foi possível apurar, nunca foram empregadas no contexto de experimento didático de produção de biodiesel para evidenciar o sucesso da reação. Do exposto, nas aulas experimentais em instituições onde o espectrômetro de RMN é inacessível, é completamente seguro aplicar o procedimento de diagnóstico por IV para comprovar a reação de transesterificação, aliando-a a outra análise físico-química simples (CCD, teste de combustão), sem prejuízo do valor pedagógico do experimento.

Uma característica dos óleos comestíveis que é muito comentada e comparada pela população em geral, é o seu grau de insaturação (GI). Neste sentido, existem descrições de determinação do GI de óleos e gorduras empregando RMN, inclusive em algumas propostas de aulas de graduação. ${ }^{22}$ Todavia, esta medida ainda não foi aplicada em aulas de preparação de biodiesel. Assim, para explorar ao máximo o potencial didático do experimento aqui apresentado, propomos também avaliar o GI dos óleos.

Uma vez realizada a distinção entre triglicerídeo e biodiesel é fácil perceber, na comparação dos espectros de RMN de 90 MHz, a

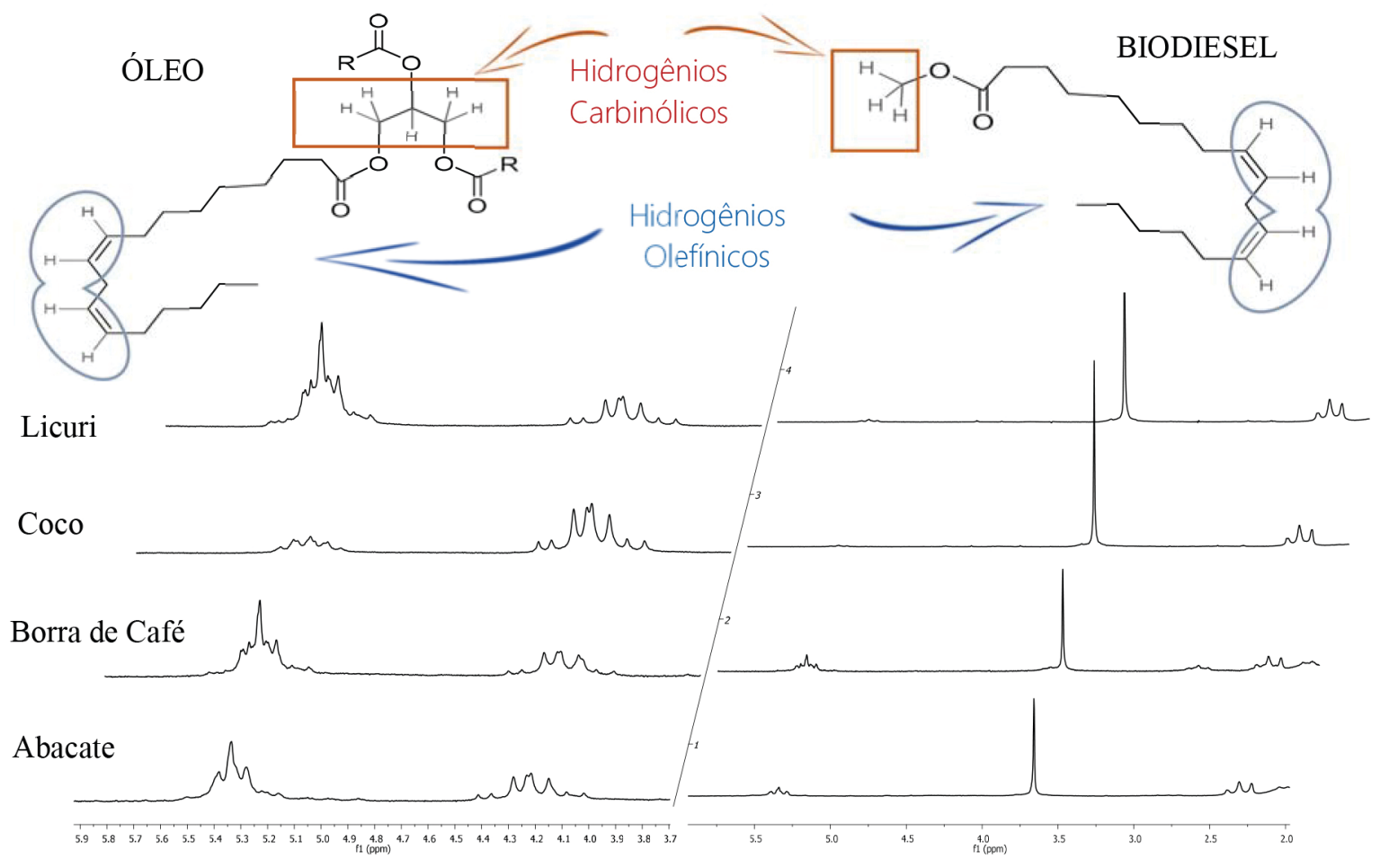

Figura 3. Espectros parciais de $\mathrm{RMN} \mathrm{de}{ }^{1} \mathrm{H}\left(\mathrm{CDCl}_{3}, 90 \mathrm{MHz}\right)$ dos óleos e biodieseis 


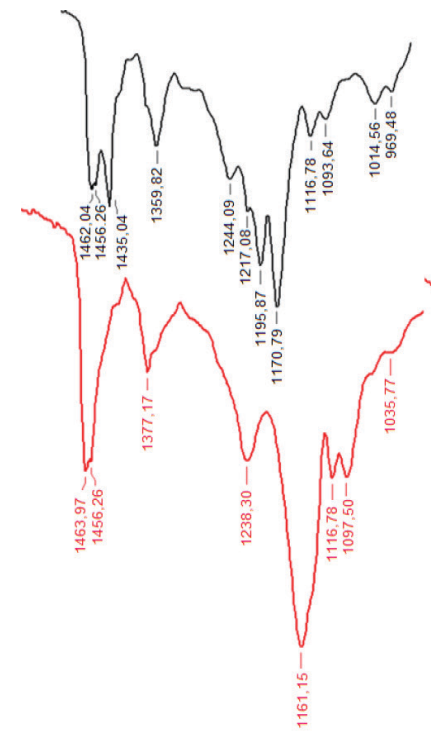

Abacate

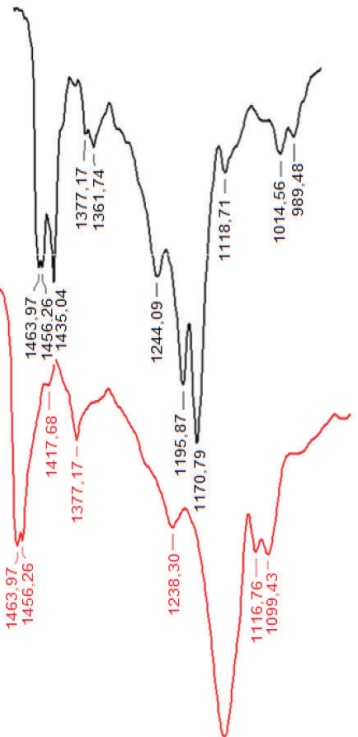

Borra de café
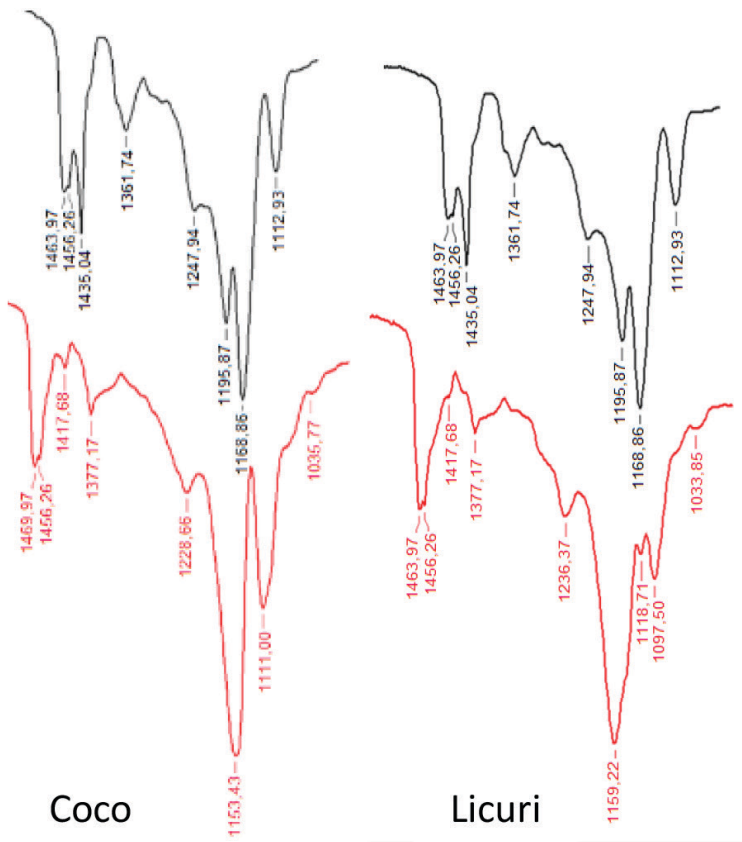

Figura 4. Intervalo dos espectros na região do infravermelho (1500-1000 $\mathrm{cm}^{-1}$, ATR) do óleo (abaixo) e o biodiesel (acima) das biomassas alternativas estudadas

diferença da quantidade de hidrogênios olefínicos entre os óleos e mensurar o GI de cada um deles. Uma primeira inspeção visual da intensidade relativa dos sinais olefínicos em $\delta$ 5,00-5,60 ppm com os dos metilênicos carbinólicos da porção glicerina dos triglicerídeos em $\delta$ 4,00-4,50 ppm já é capaz de indicar que o óleo de coco é o mais saturado dos triglicerídeos isolados, e que os mais insaturados são, nesta ordem, lícuri, borra de café é abacate, Figura 3.

Para quantificar o GI dos óleos empregando-se RMN de ${ }^{1} \mathrm{H}$ é necessário calcular a razão entre as integrações dos sinais olefínicos e carbinólicos dos óleos de cada biomassa. O sinal do hidrogênio metínico da porção glicerina dos triglicerídeos encontra-se sobreposto aos sinais dos hidrogênios olefínicos $(\mathrm{OCH}+\mathbf{H C}=\mathrm{CH}: \delta 5,00-5,60$ ppm$)$. Como o sinal do OCH da glicerina é comum a todos triglicerídeos, mas a quantidade de insaturações é variável, é possível verificar o grau de insaturação dos óleos comparando-se a integração dos sinais em $\delta 5,00-5,60$ ppm, subtraindo a contribuição relativa de um hidrogênio (referente ao OCH), com os dos metilênicos carbinólicos da porção glicerina dos triglicerídeos (OCH $\left.\mathbf{H}_{2}: \delta 4,00-4,50 \mathrm{ppm}\right)$.

Para exemplificar o cálculo do GI, na Figura 5 é apresentado o intervalo do espectro de RMN de hidrogênio para o óleo de licuri, onde a integração dos hidrogênios metilênicos carbinólicos da porção glicerina do triglicerídeo em $\delta 4,00-4,50$ ppm foi normalizada para quatro hidrogênios pois existem duas unidades $\mathrm{OCH}_{2}$ da porção glicerina do óleo que se encontram neste intervalo de deslocamento químico. Com esta normalização, a integração do sinal dos hidrogênios em $\delta$ 5,00-5,60 ppm assumiu o valor 10,61, mas como nesse intervalo temos a sobreposição do outro $\mathrm{H}$ referente à porção da glicerina do óleo e também os hidrogênios olefínicos do óleo, basta subtrair uma unidade para sabermos a intensidade da integração referente apenas aos hidrogênios olefínicos. Dessa forma, chega-se ao valor 9,61 que resulta na relação GI = 9,61/4 =2,40 para o óleo de licuri. Os dados normalizados da integração e o GI dos óleos estão indicados na Tabela 1. Pode-se verificar que o óleo de coco é o mais saturado dos triglicerídeos isolados, pois apresenta o menor valor de GI, e que os mais insaturados são, nesta ordem, lícuri, borra de café e abacate, Tabela 1.

É possível empregar os espectros de $\mathrm{RMN}$ de ${ }^{1} \mathrm{H}$ para calcular a conversão obtida de cada biodiesel produzido. ${ }^{23,24}$ Para isto, são consideradas as integrações dos sinais dos hidrogênios da metoxila

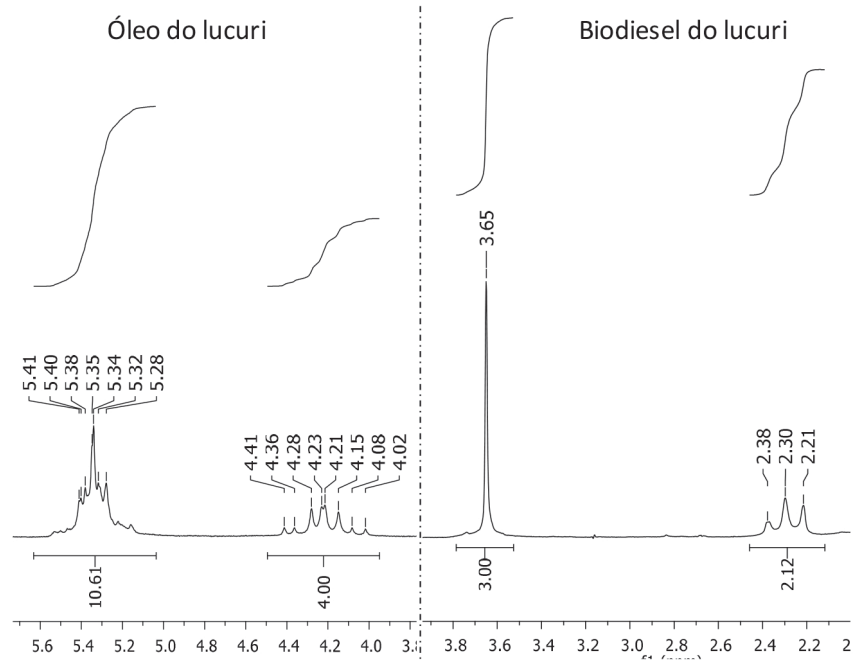

Figura 5. Intervalos dos espectros de $\mathrm{RMN} \mathrm{de}{ }^{1} \mathrm{H}\left(\mathrm{CDCl}_{3}, 90 \mathrm{MHz}\right)$ do óleo e do biodiesel do licuri para o cálculo do grau de insaturação do óleo e da conversão do biodiesel, respectivamente

em $\delta 3,7$ ppm e do carbono metilênico alfa à carbonila em $\delta 2,3$ ppm e, mesmo empregando um aparelho de campo magnético baixo dedicado a experimentos de ensino, foi possível obter uma boa resolução entre estes sinais (ver Figuras 11S, 13S, 15S e 17S). A conversão em ésteres metílico é dada pela razão das duas integrações, corrigidas pelos números de hidrogênios de cada sinal, de forma que:

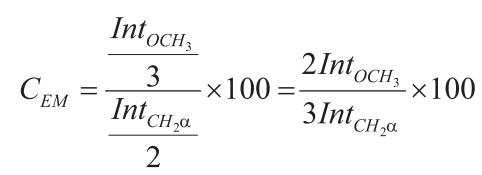

onde: $\mathrm{C}_{\mathrm{EM}}$ é a conversão em ésteres metílicos (\%); $\mathrm{Int}_{\mathrm{OCH}_{3}}$ é a integração dos sinais referentes aos hidrogênios do éster metílico, em aproximadamente $3,7 \mathrm{ppm}$; Int $\mathrm{CH}_{2} \alpha$ é a integração dos sinais referentes aos hidrogênios do grupo metilênico vizinho à carbonila do éster metílico, em aproximadamente 2,3 ppm. Este sinal está presente em 
Tabela 1. Rendimentos de óleos e biodieseis e dados do espectro de RMN de ${ }^{1} \mathrm{H}$ para avaliação do grau de insaturação (GI) dos óleos

\begin{tabular}{|c|c|c|c|c|}
\hline \multirow{2}{*}{ Biomassa } & \multirow{2}{*}{$\begin{array}{l}\text { Derivado/ Rendimento } / \\
\text { Conversão } 0^{\mathrm{b}}(\%)\end{array}$} & \multicolumn{2}{|c|}{ Integração relativa dos hidrogênios ${ }^{c}$} & \multirow{2}{*}{ GI } \\
\hline & & Olefínico & Carbinólico & \\
\hline \multirow[t]{2}{*}{ Licuri } & Óleo & $9,61^{\mathrm{d}}$ & $4^{\mathrm{e}}$ & 2,40 \\
\hline & Biodiesel/95/94 & & & \\
\hline \multirow[t]{2}{*}{ Coco } & Óleo/19 & $0,24^{\mathrm{d}}$ & $4^{e}$ & 0,06 \\
\hline & Biodiesel/68/96 & & & \\
\hline \multirow[t]{2}{*}{ Borra de café } & Óleo/4-5 & $6,04^{\mathrm{d}}$ & $4^{\mathrm{e}}$ & 1,51 \\
\hline & Biodiesel/19/100 & & & \\
\hline \multirow[t]{2}{*}{ Abacate } & Óleo/6 & $4,85^{\mathrm{d}}$ & $4^{e}$ & 1,21 \\
\hline & Biodiesel/75/89 & & & \\
\hline
\end{tabular}

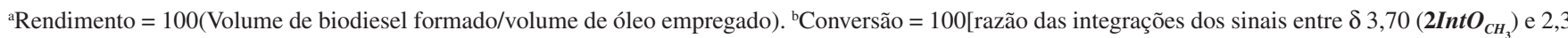

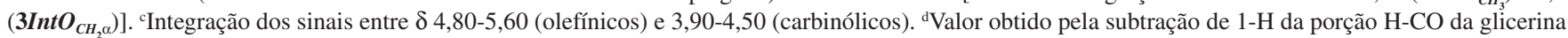
no óleo. ${ }^{\mathrm{e}}$ Normalizado para $4-\mathrm{H}$ da porção $2 \mathrm{xH}_{2} \mathrm{CO}$ da glicerina no óleo.

todas as moléculas derivadas dos triglicerídeos, incluindo resíduos não transesterificados, ácidos graxos livres, resíduos de saponificação, etc. . $^{23,24}$

Aplicando para o biodiesel de licuri com os valores apresentados na Figura 5, temos que $\mathrm{C}_{\mathrm{EM}}=(2 \times 3 / 3 \times 2,12) \times 100=94 \%$. Os valores das conversões calculados para todos biodieseis estão informados na Tabela 1.

\section{O mecanismo da catálise básica da reação de transesterificação nos textos didáticos de produção de biodiesel e a correção de um erro conceitual}

A reação de esterificação de Fischer e de transesterificação estão entre as transformações químicas presentes na formação dos profissionais da Química pois englobam conhecimentos de temas como catálise ácida e básica, equilíbrio químico e formas de deslocá-lo em favor do produto, acidez e basicidades de compostos orgânicos e a química do grupo carbonila. ${ }^{25}$

Em alguns textos didáticos sobre aspectos gerais de biodiesel e de propostas de experimentos prevalece a catálise básica na substituição acílica. ${ }^{1-11}$ Quando considerações mecanísticas são apresentadas neste cenário e $\mathrm{KOH}$ ou $\mathrm{NaOH}$ são os catalisadores, muitos mencionam textualmente e equacionam a formação de alcóxido através da reação da base hidroxila com o álcool, geralmente metanol, e consideram que o nucleófilo que ataca a carbonila é o íon metóxido. ${ }^{1,6,8,12,26}$

A formação de metóxido e água através da reação de $\mathrm{KOH}$ ou $\mathrm{NaOH}$ com $\mathrm{MeOH}$ é significativamente desfavorecida, e este tipo de erro tem se propagado nos textos de experimentos de biodiesel. A incompatibilidade de metóxido de sódio com água é bem conhecida dos químicos orgânicos que já precisaram preparar solução desse reagente, e Bucholtz, ${ }^{12}$ na sua proposta de produção didática de biodiesel empregando solução comercial de metóxido de sódio em metanol, destaca os cuidados do uso deste reagente, que reage violentamente com água.

A origem do equívoco que $\mathrm{CH}_{3} \mathrm{OH}$ seria um ácido mais forte que $\mathrm{H}_{2} \mathrm{O}$ (que resulta no erro de que metóxido poderia ser formado por reação de hidróxido com metanol) presente nos livros texto de química orgânica foi recentemente explicada num trabalho elegante de Silverstein e Heller, que resgatam o valor correto do $\mathrm{pKa}$ da $\mathrm{H}_{2} \mathrm{O}$ para 14 (e não 15,74), enquanto que o de $\mathrm{MeOH}$ é 15,54. ${ }^{27}$ Portanto, não é correto afirmar que o nucleófilo que ataca a carbonila é o íon metóxido; o nucleófilo que ataca a carbonila é o próprio metanol.

No mecanismo da substituição nucleofílica em derivados de ácidos carboxílicos é bem conhecido que a formação do intermediário tetraédrico é a etapa lenta da reação em duas etapas (adição e eliminação). ${ }^{25}$ Para acomodar o papel catalítico do $\mathrm{NaOH}$ ou $\mathrm{KOH}$ na síntese de biodiesel uma proposta de mecanismo que melhor contempla todos os fatos experimentais,$^{28}$ tendo a formação do intermediário tetraédrico como a etapa lenta, ${ }^{25}$ é apresentada na Figura 6. Assim, uma primeira etapa concertada de pseudo primeira ordem opera no ciclo catalítico onde o álcool é o solvente da reação, com a participação do catalisador $\mathrm{HO}^{-}$, e exclui a participação de metóxido como nucleófilo. ${ }^{29}$

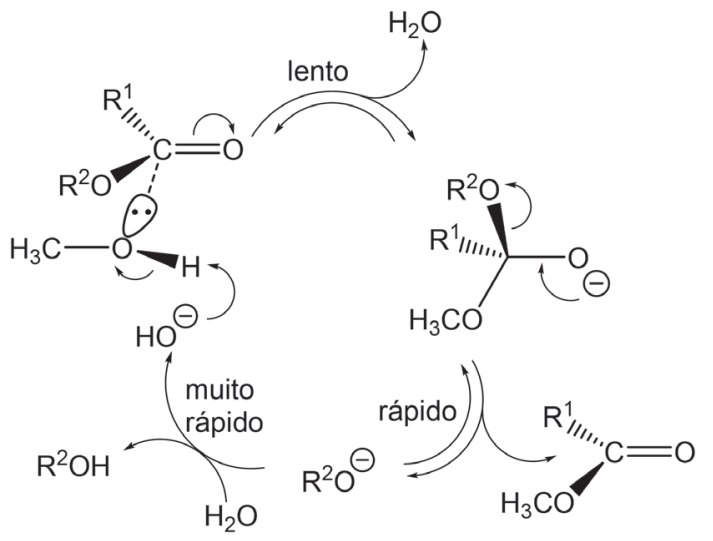

Figura 6. Ciclo catalítico do mecanismo da transesterificação na produção de biodiesel com $\mathrm{CH}_{3} \mathrm{OH}$ como solvente e catálise básica por hidróxido

\section{CONCLUSÃO}

Foi desenvolvido um conjunto de experimentos integrados de extração de óleos e produção dos respectivos biodieseis de abacate, coco, borra de café e licuri, adequado para aulas experimentais de química orgânica, que reforça a adequação de biomassa como tema transversal para a formação dos profissionais da química e contribui para o fortalecimento do ensino de Química Verde, pois aproveita biomassas não convencionais que são desperdiçadas sem uso, como a borra de café e o excedente da produção de abacate ou do fruto eventualmente descartado por ser considerado inadequado para consumo.

A aula resgata a habilidade dos químicos na extração de óleos de fontes variadas, empregando técnicas diversas e complementares, preservando assim um saber tradicional, com destaque para a obtenção do óleo a partir do leite de coco, sendo a primeira descrição desta abordagem para aula experimental, e também do abacate como biomassa para biodiesel. Além desses aspectos, a proposta intensifica a 
interpretação do espectro da região do infravermelho na diferenciação do óleo e do biodiesel, e revisita a proposta mecanística da reação de produção de biodiesel.

\section{PARTE EXPERIMENTAL}

Os espectros na região do infravermelho foram obtidos na forma de filme (ATR) em um aparelho SHIMADZU IR Affinity-1, e os espectros de RMN $\left(\mathrm{CDCl}_{3}\right)$ foram obtidos em $90 \mathrm{MHz}$ para ${ }^{1} \mathrm{H}$ empregando o aparelho Anasazi Eft-90. Abacate, pó de café, leite de coco e óleo de licuri foram adquiridos em mercado local.

\section{Extração do óleo de abacate}

Amasse de forma mecânica, com auxílio de um garfo, $200 \mathrm{~g}$ de polpa de abacate até textura homogênea. Transfira para uma forma de alumínio e distribua pela superfície até formar uma fina camada. Aqueça em estufa a $60{ }^{\circ} \mathrm{C}$ por $12 \mathrm{~h}$. Transfira a polpa desidratada para um extrator Soxhlet acoplado a um balão de $500 \mathrm{~mL}$, contendo $300 \mathrm{~mL}$ de hexano. Após 4 extrações cessar o aquecimento, resfrie o balão até temperatura ambiente e elimine o hexano em um evaporador rotatório. Foi obtido $14 \mathrm{~mL}$ de um óleo verde.

\section{Extração do óleo da borra de café}

Após preparar a bebida do café, coloque a borra para secar ao ar dois dias e acondicione na geladeira para evitar proliferação de fungos. Pese $50 \mathrm{~g}$ da borra de café em um Erlenmeyer de $500 \mathrm{~mL}$ e adicione $200 \mathrm{~mL}$ de hexano. Aqueça a mistura em placa por $45 \mathrm{~min}$ com leve fervura em capela com exaustão. Filtre em papel de filtro e transfira o filtrado para um balão previamente pesado. Elimine o hexano em evaporador rotatório e pese o balão contendo o óleo. Foram obtidos $2,34 \pm 0,21 \mathrm{~g}$, equivalente a 2,05 $\pm 0,15 \mathrm{~mL}$ de óleo, numa triplicata.

\section{Extração do óleo a partir do leite de coco}

Pese $300 \mathrm{~g}$ de leite de coco comercial (marca SOCOCO) e transfira para recipiente de vidro temperado. Cubra o recipiente com filme de PVC, faça pequenos furos na superfície e coloque em forno micro-ondas doméstico. Deixe evaporar a água do leite de coco por aproximadamente $23 \mathrm{~min}$ em potência máxima. A cada intervalo de 5 min pare o aquecimento, abra a porta do forno de micro-ondas e deixe esfriar por $1 \mathrm{~min}$. Ao término da evaporação deixe o recipiente de vidro esfriar (CUIDADO) até a temperatura ambiente. Filtre o óleo extraído à vácuo com auxílio de carvão ativado e utilize $60 \mathrm{~mL}$ de hexano para lavar do resíduo. Transfira o filtrado para um balão previamente pesado, elimine o hexano em evaporador rotatório e pese o balão contendo o óleo. Foram obtidos $58 \mathrm{~g}$ de óleo de coco equivalendo a $64 \mathrm{~mL}$.

\section{Obtenção de biodiesel do óleo de abacate}

Em um balão de $50 \mathrm{~mL}$, adicione $10 \mathrm{~mL}$ do óleo de abacate e 3,5 mL de solução metanólica de $\mathrm{KOH}$ previamente preparada com $0,2250 \mathrm{~g}$ de $\mathrm{KOH}$ e $5 \mathrm{~mL}$ de metanol. Adapte a um condensador de refluxo e aqueça a mistura a $45^{\circ} \mathrm{C}$, com agitação, por $15 \mathrm{~min}$. Após este tempo transfira para um funil de separação, descarte a fase aquosa e faça lavagens sucessivas da fase orgânica com $5 \mathrm{~mL}$ de solução de $\mathrm{HCl}$ a $0,5 \%$ (v/v), $5 \mathrm{~mL}$ de solução saturada de $\mathrm{NaCl}$ e por fim lavagem com $5 \mathrm{~mL}$ de água destilada. Remova resíduo de água utilizando sulfato de sódio anidro. Transfira o produto para um balão previamente pesado. Foram obtidos $7,5 \mathrm{~mL}$ do biodiesel de coloração verde.

\section{Obtenção de biodiesel do óleo da borra de café}

Em um balão de $25 \mathrm{~mL}$, adicione $1,5 \mathrm{~mL}$ do óleo da borra de café e $0,5 \mathrm{~mL}$ de uma solução metanólica de $\mathrm{KOH}$ previamente preparada com $0,2250 \mathrm{~g}$ de $\mathrm{KOH}$ e $5 \mathrm{~mL}$ de metanol. Adapte a um condensador de refluxo e aqueça a mistura a $45^{\circ} \mathrm{C}$, com agitação, por $10 \mathrm{~min}$. Faça a lavagem e secagem da mesma forma descrita para o biodiesel de abacate. Foi obtido $0,3 \mathrm{~mL}$ do biodiesel.

\section{Obtenção de biodiesel do óleo de coco}

Em um balão de $25 \mathrm{~mL}$, adicione $1,50 \mathrm{~mL}$ do óleo de coco previamente extraído e 1,64 mL de solução metanólica de $\mathrm{KOH}$ previamente preparada com $0,2250 \mathrm{~g}$ de $\mathrm{KOH}$ e $5 \mathrm{~mL}$ de metanol. Adapte a um condensador de refluxo e aqueça a mistura a $45^{\circ} \mathrm{C}$, com agitação, por 10 min. Faça a lavagem e secagem da mesma forma descrita para o biodiesel de abacate. Foi obtido $1,02 \mathrm{~mL}$ do biodiesel incolor, com leve odor de coco.

\section{Obtenção de biodiesel do óleo de licuri}

Em um balão de $50 \mathrm{~mL}$, adicione $10 \mathrm{~mL}$ do óleo de licuri e 3,5 $\mathrm{mL}$ de uma solução metanólica de $\mathrm{KOH}$ previamente preparada com $0,2250 \mathrm{~g}$ de $\mathrm{KOH}$ e $5 \mathrm{~mL}$ de metanol. Adapte a um condensador de refluxo e aqueça a mistura a $45^{\circ} \mathrm{C}$, com agitação, por $15 \mathrm{~min}$. Faça a lavagem e secagem da mesma forma descrita para o biodiesel de abacate. Foram obtidos 9,5 mL do biodiesel, de coloração amarela.

\section{MATERIAL SUPLEMENTAR}

Fotos da sequência da produção do óleo de coco, espectros na região do infravermelho e de $\mathrm{RMN}$ de ${ }^{1} \mathrm{H}$ estão disponíveis em http:// quimicanova.sbq.org.br, na forma de arquivo PDF, com acesso livre.

\section{AGRADECIMENTOS}

Os autores agradecem o suporte financeiro do Conselho Nacional de Desenvolvimento Científico e Tecnológico - CNPq, Coordenação de Aperfeiçoamento de Pessoal de Nível Superior - CAPES, e Fundação de Amparo à Pesquisa do Estado da Bahia - FAPESB. Também agradecemos as bolsas de pós-graduação da CAPES de M. C. Rodrigues e R. R. Mattos, e ao CNPq pelas bolsas de produtividade em pesquisa de S. Cunha e L. S. G. Teixeira. Agradecemos ao Professores S. Capim (IFBaiano) pelas análises de RMN e ao Professor M. M. Victor (UFBA) por nos informar sobre o trabalho (Ref. 28) com o mecanismo da catálise básica.

\section{REFERÊNCIAS}

1. Rinaldi, R.; Garcia, C.; Marciniuk, L. L.; Rossi, A. V.; Schuchardt, U.; Quim. Nova 2007, 30, 1374.

2. Clarke, N. R.; Casey, J. P.; Brown, E. D.; Oneyma, E.; Donaghy, K. J.; J. Chem. Educ. 2006, 83, 257. Ver também: Akers, S. M.; Conkle, J. L.; Thomas, S. N.; Rider, K. B.; J. Chem. Educ. 2006, 83, 260; Hoffman, A. R.; J. Chem. Educ. 2011, 88, 197; Bladt, D.; Murray, S.; Gitch, B.; Trout, H.; Liberko, C.; J. Chem. Educ. 2011, 88, 201.

3. Oliveira, D. M.; Ongaratto, D. P.; Fontoura, L. A. M.; Naciuk, F. F.; Santos, V. O. B; Kunz, J. D.; Marques, M. V.; Souza, A. O.; Pereira, C. M. P.; Samios, D.; Quim. Nova 2013, 36, 734.

4. De La Rosa, P.; Azurin, K. A.; Page, M. F. Z.; J. Chem. Educ. 2014, 91, 1689.

5. Goldstein, S. W.; J. Chem. Educ. 2014, 91, 1693

6. Behnia, M. S.; Emerson, D. W.; Steinberg, S. M.; Alwis, R. M.; Dueñas, J. A.; Serafino, J. O.; J. Chem. Educ. 2011, 88, 1290.

7. Ault, A. P.; Pomeroy, R.; J. Chem. Educ. 2012, 89, 243.

8. Pohl, N. L. B.; Streff, J. M.; Brokman, S.; J. Chem. Educ. 2012, 89, 1053.

9. Pierce, K. M.; Schale, S. P.; Le, T. M.; Larson, J. C.; J. Chem. Educ. 2011, 8,806 . 
10. Daconta, L. V.; Minger, T.; Nedelkova, V.; Zikopoulos, J. N.; J. Chem. Educ. 2015, 92, 1741

11. Bendall, S.; Birdsall-Wilson, M.; Jenkins, R.; Chew, Y. M. J.; Chuck, C. J.; J. Chem. Educ. 2015, 92, 683.

12. Ramos, L. P.; Kothe, V.; César-Oliveira. M. A. F.; Muniz-Wypych, A. S.; Nakagaki, S.; Krieger, N.; Wypych, F.; Cordeiro, C. S., Rev. Virtual Quim. 2008, 9, 317; Silverman, J. R.; J. Chem. Educ. 2016, 93, 1679; Santos, A. P. B.; Pinto, A.; Quim. Nova. Esc. 2009, 31, 58; Oliveira, F. C. C.; Suarez, P. A. Z.; Santos, W. L. P.; Quim. Nova Esc. 2008, 3; Castro, H. F.; Mendel, A. A.; Santos, J. C.; Aguiar, C. L.; Quim. Nova 2004, 27, 146; Costa Neto, P. R.; Rossi, L. F. S.; Zagonel, G. F.; Ramos, L. P.; Quim. Nova 2000, 23, 531; Bucholtz, E.; J. Chem. Educ. 2007, 84, 296; Stout, R.; J. Chem. Educ. 2007, 84, 1765.

13. Cunha, S.; Fontes, T.; Araújo, D. M., Riatto; V. B.; Quim. Nova 2018, 41, 116; Cunha, S.; Matos, J. S.; Quim. Nova 2017, 40, 1253; Riatto, V. B.; Victor, M. M., Cunha, S.; Magalhães, A. C. R., Cruz, F. T.; Carriço, C. S., Quim. Nova 2015, 38, 727; Cunha, S.; Costa, O. B. S.; Santana, L. L. B.; Lopes, W. A.; Quim. Nova 2015, 38, 874. Cunha, S.; Iunes, C. E. M.; Oliveira, C. C.; de Santana, L. L. B.; Quim. Nova 2015, 38, 1125; Cunha, S.; Santos Filho, R. F.; Riatto, V. B.; Dourado, G. A. A.; Quim. Nova 2013, 36, 190. Cunha, S.; de Santana, L. L. B.; Quim. Nova 2012, 35, 642; Cunha, S.; Lustosa, D. M.; Conceição, N. D.; Fascio, M.; Magalhães, V.; Quim. Nova 2012, 35, 638.

14. Durán, C. A. A.; Tsukui, A.; Santos, F. K. F; Martinez, S. T.; Bizzo, H. R.; Rezende, C. M., Rev. Virtual Quim. 2017, 9, 107.

15. Bendinskas, K.; Weber, B.; Nsouli, T.; Nguyen, H. V.; Joyce, C.; Niri, V., Jaskolla, T. W.; J. Chem. Educ. 2014, 91, 1697.

16. https://365salvador.wordpress.com/2013/05/24/24-de-maio-carrinho-decafe/, acessada em Fevereiro de 2018.

17. https://www.youtube.com/watch?v=NErY0ssPEm0, acessada em Fevereiro de 2018.

18. Crowther, M. W.; J. Chem. Educ. 2008, 85, 1550.

19. Sanli, H., Canakci, M.; Energy Fuels 2008, 22, 2713.
20 Bladt, D.; Murray, S.; Gitch, B.; Trout, H.; Liberko, C.; J. Chem. Educ. 2011, 88, 201.

21 Rabelo, S. N.; Ferraz, V. P.; Oliveira, L. S.; Franca, A. S. Int. J. Environ. Sci. Development 2015, 6, 964

22. Hartel, A. M., Moore, A. C.; J. Chem. Educ. 2014, 91, 1702; Fry, C. G.; Hofstetter, H.; Bowman, M. D.; J. Chem. Educ. 2017, 94, 1319.

23. Guzatto, R.; Martini, T. L.; Samios, D.; Fuel Process. Technol. 2011, 92 , 2083.

24 Gelbard, G.; Brès, O.; Vargas, R. M.; Vielfaure, F.; Schuchardt, U. F.; J. Am. Oil Chem. Soc. 1995, 72, 1239.

25. Costa, P. R. R.; Pilli, R. A.; Pinheiro, S.; Vasconcellos, M. L. A. A.; Substâncias Carboniladas e Derivados, Artmed Editora: Porto Alegre, 2003, pp. 252; A alternativa do ataque do álcool à carbonila e, só então, o HO- subtrair o hidrogênio do álcool, ao mesmo tempo que o oxigênio refaz a ligação dupla ao carbono não reflete a formação do intermediário tetraédrico como etapa lenta.

26 Meneghetti, S. M. P.; Meneghetti, M. R.; Brito, Y. C.; Rev. Virtual Quim. 2013, 5, 63 .

27. A análise detalhada dos argumentos termodinâmicos que comprovam que a $\mathrm{H}_{2} \mathrm{O}$ é um ácido mais forte que o $\mathrm{MeOH}$ estão fora do escopo do trabalho aqui descrito, mas podem ser verificados neste artigo pedagógico e na bibliografia adicional aí citada: Silverstein, T. P.; Heller, S. T.; J. Chem, Educ. 2017, 94, 690.

28. Tang, Z.; Wang L.; Yang, J.; Eur. J. Lipid Sci. Technol. 2008, 110, 747.

29. A reação é de pseudo primeira ordem pois o álcool atua como solvente e, ao mesmo tempo, reagente, e está em quantidade superior ao triglicerídeo. A entidade química $\mathrm{HO}^{-}$atua como catalisador e, neste caso, tem ordem de reação igual a zero. Portanto, apesar da ordem global da reação ser 2, a [álcool] ${ }^{\mathrm{x}}$ (onde $\mathrm{x}$ é a ordem de reação em relação ao álcool) é incorporada na constante de velocidade e a equação geral tem a seguinte forma: $\mathrm{v}=\mathrm{k}^{\prime}[\text { triglicerídeo }]^{y}[\text { catalisador }]^{2}$, em que $\mathrm{z}=0$ e $\mathrm{k}^{\prime}=\mathrm{k}[\text { álcool }]^{\mathrm{x}}$, sendo $\mathrm{x}+\mathrm{y}=2$. 